\title{
Predictors Modifying the Outcome of Tuberculous Meningitis (TBM) in Adults: A Hospital Based Study in Bangladesh
}

\author{
Kamal Ahmed', Mohammad Enayet Hussain², Md Azharul Hoque ${ }^{3}$, Uttam Kumar Saha4, \\ Rajib Nayan Chowdhury ${ }^{5}$, Rafiqul Islam ${ }^{6}$, Md. Mubin Uddin Akhanji ${ }^{7}$, \\ Md. Shahidul Islam, Md Badrul Alam, Quazi Deen Mohammad ${ }^{10}$
}

\begin{abstract}
${ }^{1}$ Professor, Department of Neurology, North East Medical College, Sylhet, Bangladesh; ${ }^{2}$ Associate Professor, Department of Neurology, National Institute of Neurosciences \& Hospital, Dhaka, Bangladesh; ${ }^{3}$ Professor \& Former Head, Department of Neurology, National Institute of Neurosciences \& Hospital, Dhaka, Bangladesh; ${ }^{4}$ Professor (Former), Department of Neurology, National Institute of Neurosciences \& Hospital, Dhaka, Bangladesh; ${ }^{5}$ Professor \& Head, Department of Neurophysiology, National Institute of Neurosciences \& Hospital, Dhaka, Bangladesh; ${ }^{6}$ Associate Professor, Department of Pharmacology, National Institute of Neurosciences \& Hospital, Dhaka, Bangladesh; ${ }^{7}$ Assistant Professor, Department of Psychiatry, Sylhet MAG Osmani Medical College, Sylhet, Bangladesh; ${ }^{8}$ Junior Consultant (Medicine), Sarkari Karmachari Hospital, Dhaka, Bangladesh; ${ }^{9}$ Joint Director \& Professor of Neurology, National Institute of Neurosciences \& Hospital, Dhaka, Bangladesh; 10Director \& Professor of Neurology, National Institute of Neurosciences \& Hospital, Dhaka, Bangladesh
\end{abstract}

[Received on: 22 November 2020; Accepted on: 12 December 2020; Published: 1 January 2021]

\begin{abstract}
Background: Outcome of TBM can be modified by several predictors. Objective: This study was undertaken to evaluate the predictors of outcome of tuberculous meningitis (TBM) at 6 and 9 months. Methodology: This hospital based prospective cohort study was carried out from October, 2016 to September, 2017 (1 year) in the in-patient Department of Neurology at the National Institute of Neurosciences \& Hospital (NINS \& H), Dhaka, Bangladesh. All the patients with age 18 years or more of both sexes with features of TBM fulfilling the case definition criteria was included as the study population. The outcome was measured at 6 and 9 months by modified Rankin Scale (mRS) with no disability (score=0-1), mild disability (score $=2$ ), moderate disability $($ score $=3-4)$, severe disability $($ score $=5)$ and dead $($ score $=6)$. For statistical analysis outcome was classified as death and survival group. A number of clinical, laboratory and radiological parameters were evaluated initially by univariate and finally multiple regression analysis. Results: A total 54 TBM patients were included in this study. Over $70 \%$ of the patients were adolescent or young adult $(<30$ years) with mean age of $28.2 \pm 12.3$ years and $63 \%$ were female. Staging of the TBM showed that nearly half (48.1\%) were at stage II and $37 \%$ cases were in stage III disease. Baseline imaging (CT-scan and MRI) showed basal meningeal enhancement in $40.7 \%$ cases, hydrocephalus in $40.7 \%$, infarction $46.3 \%$ and tuberculoma in $29.6 \%$ cases. Final diagnosis was established as definite TBM in $3(5.6 \%)$ cases, probable TBM $30(55.6 \%)$ and possible TBM in $21(38.9 \%)$ cases. In terms of 6-months outcome, 16(29.6\%) cases died and 10(18.5\%) had recovered without any neurological sequelae; however, mild, moderate and severe disability were in $11.1 \%, 27.8 \%$ and $13 \%$ cases respectively. At the 9 months of evaluation $13(24.0 \%)$ had complete recovery without any neurological sequelae, 22 (40.9\%) patients survived with various degree of disabilities like visual impairment, hemi or paraplegia, cognitive impairment, rests died giving a total mortality of $19(35.1 \%)$. In univariate analysis, age $>50$ years $(p=0.019)$, duration of illness before initiation of treatment $(>45 d)(p=0.041)$, convulsion $(p=0.010)$, altered sensorium $(p<0.001)$, delayed initiation of treatment $>1$ month $(\mathrm{p}=0.041)$ and stage III TBM $(\mathrm{p}<0.001)$ were significantly associated with mortality. In multivariate analyses stage III TBM $(\mathrm{p}=0.004)$, altered sensorium $(\mathrm{p}=0.036)$, delayed initiation of treatment $>1$ month $(\mathrm{p}=0.043)$ emerged as independent predictors of mortality. Conclusions: In conclusion stage III TBM, altered sensorium and delayed initiation of treatment more than 1 month are the independent predictors of mortality in TBM patients. [Journal of National Institute of Neurosciences Bangladesh, January 2021;7(1): 14-19]
\end{abstract}

Keywords: Predictors; Outcome; Tuberculous Meningitis; TBM

Correspondence: : Dr. Kamal Ahmed, Professor, Department of Neurology, North East Medical College, Sylhet, Bangladesh; Cell no.: +8801717540022; Email: docdrkamal@gmail.com

Conflict of interest: None

Funding agency: Any of the author did not receive any external funding for this study.

Contribution to authors: Ahmed $\mathrm{K}$ was involved in the concept, study design and data collection. The rest of the authors were involved in data collection and partially writing and editing the manuscript.

How to cite this article: Ahmed K, Hussain ME, Hoque MA, Saha UK, Chowdhury RN, Akhanji MMU, Islam MS, Alam MB, Mohammad QD. Predictors Modifying the Outcome of Tuberculous Meningitis (TBM) in Adults: A Hospital Based Study in Bangladesh. J Natl Inst Neurosci Bangladesh, 2021;7(1): 14-19

Copyright: (C2021. Ahmed et al. Published by Journal of National Institute of Neurosciences Bangladesh. This article is published under the Creative Commons CC BY-NC License (https://creativecommons.org/licenses/by-nc/4.0/). This license permits use, distribution and reproduction in any medium, provided the original work is properly cited, and is not used for commercial purposes. 


\section{Introduction}

Tuberculosis (TB) is a global pandemic and is caused by the Mycobacterium tuberculosis complex ${ }^{1}$. It causes ill-health for approximately 10 million people each year and is one of the top ten causes of death worldwide ${ }^{2}$ and second leading causes of death from an infectious disease after $\mathrm{HIV}^{3}$. Bangladesh is one of the high burden countries (HBCs) among 30 for tuberculosis reported by WHO with the incidence of 221/100000 and mortality 40/100000 annually ${ }^{2}$.

TB most commonly affects the lungs (pulmonary TB), although it can also affect other organs and systems (extra pulmonary TB). About $15.0 \%$ to $20.0 \%$ of TB cases are extra pulmonary ${ }^{4-5}$. The World Health Organization (WHO) reported 0.8 million extra pulmonary TB cases worldwide in 2013. TBM is the severe form of CNS tuberculosis ${ }^{6}$. The relative incidence of this disease is $0.4 \%$ to $1.0 \%$ of all cases of $\mathrm{TB}^{7-9}$. The disease affects all the age groups. However recent data suggests that 15 years or more age group comprises about $88.0 \%$ of all patients ${ }^{10}$. The actual incidence and prevalence of TBM is not yet clearly defined in our country. The worldwide mortality rate of this disease is $20.0 \%$ to $69.0 \%$ and about half of the survivors developed neurological sequelae like visual loss, motor and cognitive deficits ${ }^{5,711-13}$. Early diagnosis is an essential component in management of tuberculous meningitis to prevent mortality and morbidity ${ }^{5}$. However prediction of ultimate outcome of this condition is difficult due to its prolonged course, the virulence of the infecting agent, non specific pathological mechanisms, difference in host immunity and CSF penetration for ATT $^{12,14}$.

Many prognostic predictors have been studied globally to predict the outcome of these serious disorders. Among them important are the stage of the disease (stage I, II, III), age, sex, seizure, $\mathrm{H} / \mathrm{O}$ close contact with tuberculous patient, underlying co morbidities, duration of illness, fever, headache, visual impairment, alteration of consciousness, mental status abnormalities, neck stiffness, cranial nerve palsy, changes in fundus, focal neurological deficit, extra meningeal tuberculosis, CSF cell (TC of WBC), protein, glucose, image (hydrocephalus, infarction, basal meningeal enhancement, tuberculoma), timing of initiation of anti-TB drugs, treatment with corticosteroid, drug toxicity, shunt surgery and neurophysiological findings (EEG, motor and somatosensory evoked potentials) ${ }^{7,13-15}$. Outcome of TBM depend on more than one variable, in that circumstances multivariate analysis is a useful method for it's benefit of determining the effect of each variable while controlling the influence of the others ${ }^{16}$. As evidence suggest that neurological status in TBM patient changes at 6 and 9 months ${ }^{13,16-17}$. The purpose of the present study was to identify the prognostic predictors of outcome in adult of TB meningitis in Bangladesh at 6 and 9 months.

\section{Methodology}

This present study was designed as hospital-based

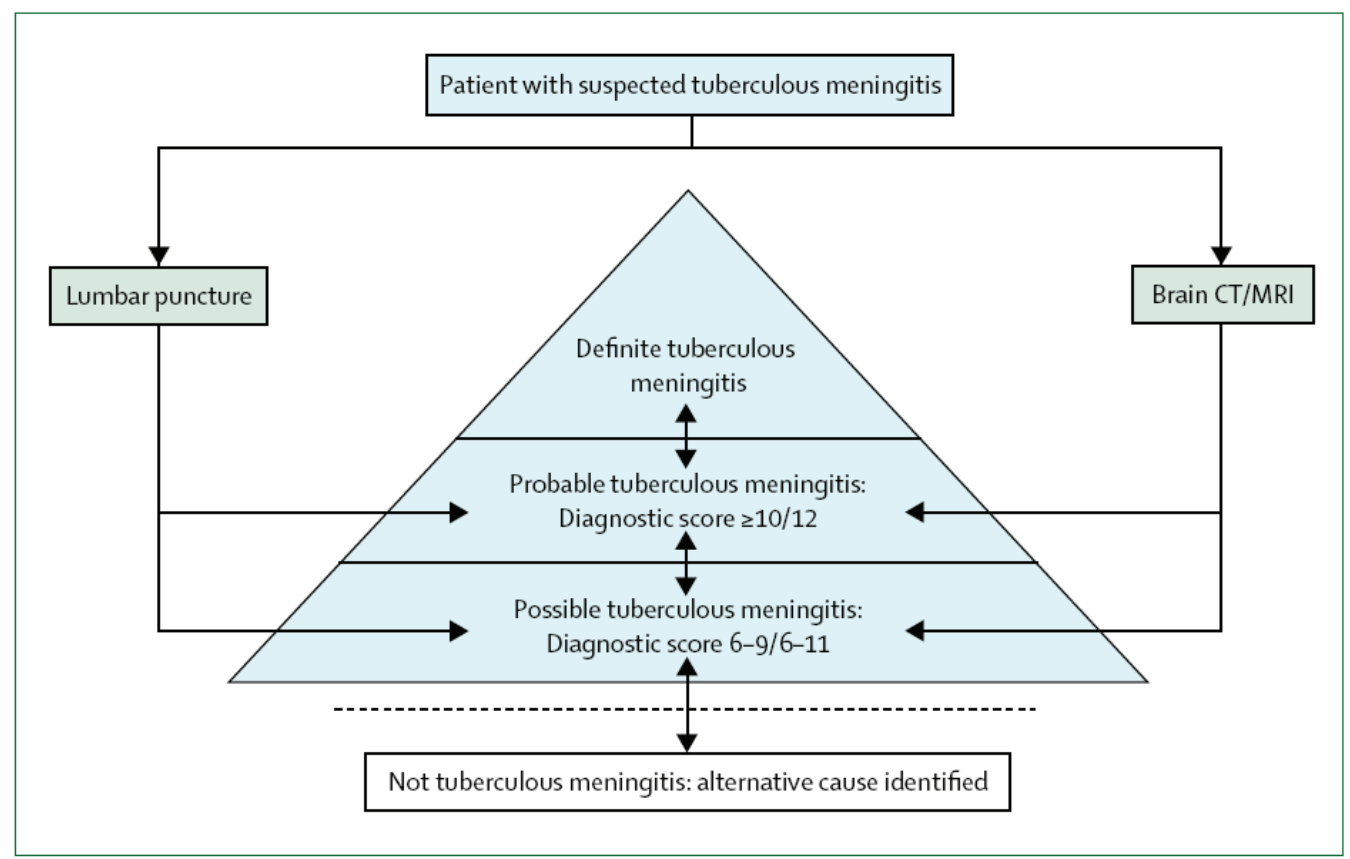

Figure I: Categories for patients with suspected tuberculous meningitis ${ }^{18}$ 
prospective cohort study conducted in the inpatient Department of Neurology at the National Institute of Neurosciences \& Hospital (NINS \& H), Dhaka, Bangladesh. The patients with features of TBM fulfilling the "consensus case definition criteria for $\mathrm{TBM}^{18}$ were included as the study population. According to the consensus case definition the cases were categorized as definite, probable, possible and not TBM group. Not TBM patients were excluded from the study. After the enrollment, necessary investigation including CSF study and neuroimaging like MRI of brain with contrast were performed. Inclusion criteria were patients of 18 years or more of both sex categorized as definite, probable and possible Tuberculous Meningitis. Exclusion criteria were positive CSF for Gram or India Ink stain, ICSOL, serum bilirubin $>2.5 \times$ ULN, ALT $>5 \times$ ULN, S. Creatinine $>3 \times$ ULN, pregnancy. All the patients were treated initially (intensive phase) for 2 months and then a maintenance phase for 10 months with standard anti TB four drugs regimen according to weight based NTP schedule under DOTS along with corticosteroid coverage ${ }^{3,17,19}$. CSF diversion surgery was considered in selective cases of hydrocephalus. Pyridoxine was given with isoniazid therapy throughout the treatment. Paradoxical response was managed with short course of corticosteroid in standard dose and duration ${ }^{20-21}$. Second line antituberculous therapy was used in resistance cases of first line drug according to the standard protoco $^{13,17}$. Follow-up was done at OPD of NINS\&H at 6 and 9 months. The outcome was measured at 6 and 9 months by modified Rankin Scale (mRS) with no disability (score $=0-1)$, mild disability $($ score $=2$ ), moderate disability (score $=3-4)$, severe disability $($ score $=5)$ and dead $(\text { score }=6)^{11}$. For statistical analysis outcome was classified as death and survival group. A number of clinical, laboratory and radiological parameters were evaluated initially by univariate and finally by multiple regression analysis.

Statistical Analysis: Statistical analysis of the study was done by SPSS version 25.0. Confidence interval was considered at $95.0 \%$ level. Less than 0.05 was taken as statistically significant. Univariate analysis was conducted first using Chi-square test and Fisher's Exact Test to determine association of different variables on outcome. Then independent predictor was determined on mortality using logistic regression analysis. To eliminate confounding factors in predicting the risk for mortality, variables with $p$ value $\leq 0.05$ by univariate analysis were entered into a multivariate logistic regression model for further assessment.

\section{Results}

A total 54 TBM patients were included in this study. Over $70.0 \%$ patients were adolescent or young adult (more than 30 years) with mean age of $28.2 \pm 12.3$ years with a female preponderance (63\%) (Table 1).

Table 1: Distribution of Patients by their Demographic Characteristics $(\mathrm{n}=54)$

\begin{tabular}{lcc}
\hline Demography & Frequency & Percent \\
\hline Age (Years) & 38 & 70.4 \\
$<30$ & 5 & 9.3 \\
$30-40$ & 7 & 13.0 \\
$40-50$ & 4 & 7.3 \\
$\geq 50$ & & \\
Sex & 20 & 37.0 \\
Male & 34 & 63.0 \\
Female & \\
\hline
\end{tabular}

At admission nearly half (48.1\%) were at stage II and $37 \%$ cases were in stage III disease [Table:2].

Table 2: Categorization of Patients according to the Stages $(\mathrm{n}=54)$

\begin{tabular}{lcc}
\hline Stages of TBM & Frequency & Percent \\
\hline I & 8 & 14.8 \\
II & 26 & 48.1 \\
III & 20 & 37.0 \\
Total & $\mathbf{5 4}$ & $\mathbf{1 0 0}$ \\
\hline
\end{tabular}

Baseline imaging (CT-scan and MRI) showed basal meningeal enhancement and hydrocephalus in equal number of patients $(40.7 \%)$, infarction in $46.3 \%$ and tuberculoma in $29.6 \%$ cases [Figure I].

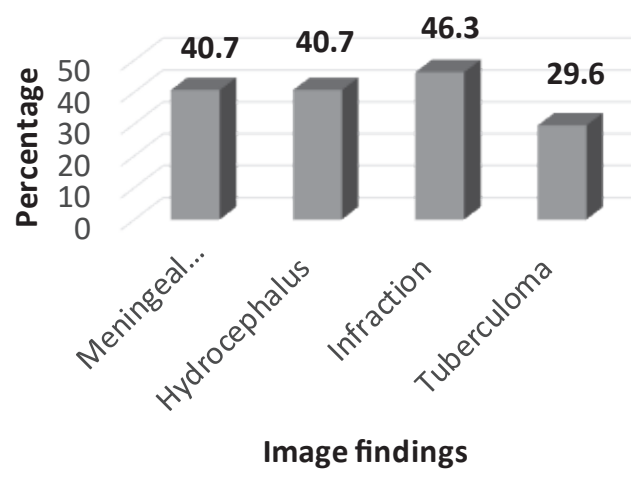

Figure I: Categories for patients with suspected tuberculous meningitis ${ }^{18}$

Table 3 shows in terms of 6-months outcome, $10(18.5 \%)$ came round without any sequalae. over one-quarter $(38.8 \%)$ had mild to moderate disability. $13 \%$ had severe disability. In this period $16(29.6 \%)$ patients died due to disease process. 
Final diagnosis was established as definite TBM in $3(5.6 \%)$ cases, probable TBM 30(55.6\%) and possible TBM in $21(38.9 \%)$ cases. In terms of 6 -months outcome, $16(29.6 \%)$ cases died while $10(18.5 \%)$ had recovered without any neurological sequelae; however, mild, moderate and severe disability were observed in $11.1 \%, 27.8 \%$ and $13 \%$ cases respectively (Table 3 ).

Table 3: Distribution of patients by their Outcome at 6 months $(\mathrm{n}=54)$

\begin{tabular}{lcc}
\hline Outcome at 6 months & Frequency & Percent \\
\hline No disability (good outcomes) & 10 & 18.5 \\
Mild / Moderate Disability & & \\
(intermediate outcomes) & 21 & 38.8 \\
Severe disability (Poor outcome) & 7 & 13.0 \\
Death & 16 & 29.6 \\
Total & $\mathbf{5 4}$ & $\mathbf{1 0 0}$ \\
\hline
\end{tabular}

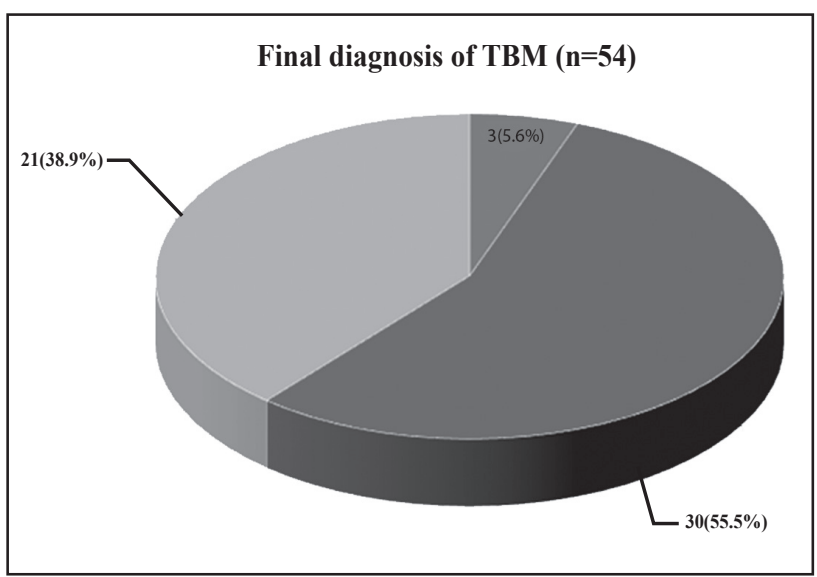

Figure II: Pie diagram showing final diagnosis in 54 cases

At the 9 months of evaluation $13(24.0 \%)$ had complete recovery without any neurological sequelae, $22(40.9 \%)$ patients survived with various degree of disabilities like visual impairment, hemi or paraplegia, cognitive impairment and rest of the patients died 19(35.1\%) (Table 4; Figure III).

Table 4: Distribution of patients by their outcome at 9 months $(\mathrm{n}=38)$

\begin{tabular}{lcc}
\hline Outcome at 9 months & Frequency & Percent \\
\hline No disability (good outcomes) & 13 & 34.2 \\
Mild / Moderate Disability & & \\
(intermediate outcomes) & 19 & 50 \\
Severe disability (Poor outcome) & 3 & 7.9 \\
Death & 3 & 7.9 \\
Total & $\mathbf{3 8}$ & $\mathbf{1 0 0}$
\end{tabular}

16 patient were died at 6 month follow up were excluded from the analysis.

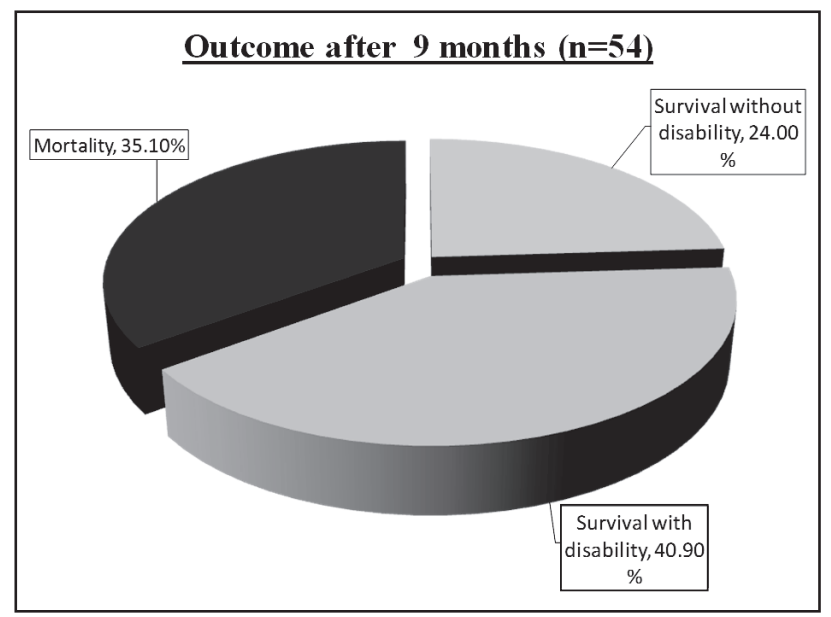

Figure III: Pie diagram showing net outcome after 9 months of follow up $(\mathrm{n}=54)$

Table 5: Univariate analysis of predictors of mortality related to clinical, CSF and diagnostic findings

\begin{tabular}{|c|c|c|c|c|}
\hline \multirow[t]{2}{*}{ Risk Factors } & \multicolumn{2}{|c|}{ Group } & \multirow[t]{2}{*}{ P value } & \multirow{2}{*}{$\begin{array}{c}\text { Relative Risk } \\
(95 \% \text { CI of RR }\end{array}$} \\
\hline & Dead $(n=19)$ & Survived $(n=35)$ & & \\
\hline Age $>50$ years & $3(15.8)$ & $1(2.9)$ & 0.019 & $2.3(1.1-4.7)$ \\
\hline Sex (Male) & $8(42.1)$ & $12(34.3)$ & 0.570 & Not computed \\
\hline Duration of illness $(>45 \mathrm{~d})$ & $12(63.2)$ & $12(34.3)$ & 0.041 & $2.1(1.0-4.6)$ \\
\hline Convulsion & $11(57.9)$ & $8(22.9)$ & 0.010 & $2.5(1.2-5.2)$ \\
\hline Altered sensorium & $13(68.4)$ & $7(20.0)$ & $<0.001$ & $3.6(1.6-8.1)$ \\
\hline Focal neurological deficit & $8(42.1)$ & $24(68.6)$ & 0.059 & Not computed \\
\hline Hemiplegia/paraplegia & $4(21.1)$ & $4(11.4)$ & 0.583 & Not computed \\
\hline Cranial nerve palsy & $7(36.8)$ & $19(54.3)$ & 0.221 & Not computed \\
\hline Optic neuritis & $2(10.5)$ & $7(20.0)$ & 0.610 & Not computed \\
\hline Papilloedema & $1(5.3)$ & $4(11.4)$ & 0.417 & Not computed \\
\hline Extra-meningeal TB & $1(5.3)$ & $9(25.7)$ & 0.064 & Not computed \\
\hline Comorbidities & $4(21.1)$ & $9(25.7)$ & 0.951 & Not computed \\
\hline Raised CSF protein & $10(52.6)$ & $17(48.6)$ & 0.776 & Not computed \\
\hline Low glucose & $13(68.4)$ & $22(62.9)$ & 0.683 & Not computed \\
\hline Delayed initiation of $\mathrm{Rx}>1$ month & $12(63.2)$ & $14(40.0)$ & 0.041 & $1.8(0.8-3.9)$ \\
\hline $\mathrm{WBC}>11000(\mathrm{cu}-\mathrm{mm})$ & $11(57.9)$ & $16(45.7)$ & 0.393 & Not computed \\
\hline Definite \& probable TBM & $10(52.6)$ & $23(65.7)$ & 0.346 & Not computed \\
\hline Stage III TBM & $14(73.7)$ & $6(17.1)$ & $<0.001$ & $4.7(2.0-11.2)$ \\
\hline CSF diversion (VP shunt) & $2(10.5)$ & $3(8.6)$ & 0.583 & Not computed \\
\hline Paradoxical response & $0(0.0)$ & $5(14.3)$ & 0.103 & Not computed \\
\hline
\end{tabular}


In univariate analysis, age $>50$ years $(p=0.019)$, duration of illness before initiation of treatment $(>45 \mathrm{~d})$ $(p=0.041)$, convulsion $(p=0.010)$, altered sensorium $(p<0.001)$, delayed initiation of treatment $>1$ month $(p=0.041)$ and stage III TBM $(p<0.001)$ were significantly associated with mortality (Table 5 ).

In multivariate analyses stage III TBM $(\mathrm{p}=0.004)$, altered sensorium $(p=0.036)$, delayed initiation of treatment $>1$ month $(\mathrm{p}=0.043)$ emerged as independent predictors of mortality (Table 6).

Table 6: Multivariate Logistic Regression Analysis Showing Predictors of Outcome in TBM

\begin{tabular}{lccc}
\hline Variables of interest & $\begin{array}{c}\text { Univariate } \\
\text { analysis } \\
\text { (p-value) }\end{array}$ & $\begin{array}{c}\text { Multivariate analysis } \\
\text { (95\% CI of RR) }\end{array}$ & \\
\hline Age $>50$ years & 0.019 & $0.9(0.09-2.5)$ & 0.488 \\
$\begin{array}{l}\text { Duration of illness } \\
(>45 \text { d) }\end{array}$ & 0.041 & $0.3(0.05-3.8)$ & 0.244 \\
Convulsion & 0.010 & $2.2(1.0-5.4)$ & 0.051 \\
Altered sensorium & $<0.001$ & $2.3(1.4-6.7)$ & 0.036 \\
$\begin{array}{l}\text { Delayed initiation of } \\
\text { Rx }>1 \text { month }\end{array}$ & 0.041 & $1.3(0.7-4.4)$ & 0.043 \\
Stage III TBM & $<0.001$ & $3.6(1.5-8.5)$ & 0.004 \\
\hline
\end{tabular}

\section{Discussion}

Among the 54 TBM patients most $(70.0 \%)$ were adolescent and young adults ( $<30$ years) with a female preponderance $(63.0 \%)$. An Indian study also found a female predominance ${ }^{20}$. Most of the patients presented at stage II (48.1\%) and stage III (37.0\%) on admission. Yasar et $\mathrm{al}^{12}$ in their study also found maximum patients at stage II on presentation.

In this series only 3 cases $(5.6 \%)$ were GeneXpert positive and classified as definite TBM. AFB was not found in any of the cases. Sensitivity of AFB stain and GeneXpert in TBM is $37.0 \%$ and $59.0 \%$ respectively, depending on the procedure, volume of CSF submitted, repetition of LPs and the capacity of laboratories and technician's experience ${ }^{18,22}$. Kalita and Misra $^{16}$ also found a very low sensitivity of AFB in CSF during evaluation of 58 TBM cases.

Baseline imaging (CT scan and MRI) findings in the present series revealed that infarction was the commonest $(46.3 \%)$ finding followed by basal meningeal enhancement and hydrocephalus in equal number of patients (40.7\%). Tuberculoma was present in $29.6 \%$ cases. However the imaging in $11(20.37 \%)$ patients revealed no abnormality. Almost similar findings were observed by Hsu et $\mathrm{al}^{13}$ during evaluation of 95 TBM patients except a lower frequency of tuberculoma in their study. On the other hand tuberculoma was found to be present in more than half of patients of TBM in study by Tai et $\mathrm{al}^{4}$.

In the present study definite diagnosis of TBM (Definite TBM) was established only in 3(5.6\%) cases which is near $(5.2 \%)$ to the study by Kalita and Misra ${ }^{16}$. The rest were probable [30(55.6\%)] and possible [21(38.9\%)]. The rate of definite TBM was more in the series by Lau et $\mathrm{al}^{8}$ involving 166 patients. In the present series the possible explanation for less number of definite TBM may be submission of conventional volume of CSF (where higher CSF volume could have yielded better), non-repetition of LPs and finally limitation of the laboratories and technician's experience.

The 6- and 9-month mortality rate in this study was $29.6 \%(16 / 54)$ and $35.2 \%(19 / 54)$ respectively which is almost similar to the mortality rate reported by Hsu et $\mathrm{al}^{13}$. Other literature also revealed similar findings ${ }^{11}$. In univariate analysis six variables [age more than 50 years, duration of illness before initiation of treatment (more than $45 \mathrm{~d}$ ), convulsion, altered sensorium, delayed initiation of treatment more than 1 month and stage III TBM] were found to be significantly associated with mortality. Among them stage III TBM, altered sensorium, delayed initiation of treatment more than 1 month emerged as independent predictors of mortality in multivariate analyses. Stage III TBM and altered sensorium (GCS) were reported as independent predictor of mortality in TBM in several studies $^{8,12,14-16,23}$. Delay in initiation of anti-TB therapy turned out to be a poor predictor of outcome in the study by Hsu et $\mathrm{al}^{13}$.

There are some limitation of the study. It was a single center study with a limited number definite TBM cases. The sample size was also relatively small for performing logistic regression analysis.

\section{Conclusion}

In conclusion, stage III TBM, altered sensorium and delay (more than 1 month) in initiation of treatment are independent predictors of mortality in TBM patient.

\section{References}

1. Gallardo CR, Rigau-Comas D, Valderrama Rodriguez A, Roqué i Figuls M, Parker LA, Caylà J, et al. Fixed-dose combinations of drugs versus single-drug formulations for treating pulmonary tuberculosis. The Cochrane Library. 2016 Jan 1.

2. World Health Organization (WHO). Global tuberculosis report 2017. 2018. [Available at:http://www.who.int/tb/publications/ global_report/gtbr2017_main_text.pdf. accessed on: 2/10/18]

3. National Tuberculosis Control Programme (NTP). National Guidelines and Operational Manual for Tuberculosis Control. 2013. 5th ed. DGHS, Dhaka. 
4. Tai ML, Mohd-Nor H, Rahmat K, Viswanathan S, Abdul Kadir KA, Ramli N, et al. Neuroimaging findings are sensitive and specific in diagnosis of tuberculous meningitis. Neurology Asia. 2017;22(1)

5. Pai M, Flores LL, Pai N, Hubbard A, Riley LW, Colford Jr JM. Diagnostic accuracy of nucleic acid amplification tests for tuberculous meningitis: a systematic review and meta-analysis. The Lancet Infectious Diseases. 2003;3(10):633-43.

6. Prasad K, Singh MB. Corticosteroids for managing tuberculous meningitis. Cochrane Database of Systematic Reviews. 2016(1).

7. Erdem H, Ozturk-Engin D, Tireli H, Kilicoglu G, Defres S, Gulsun S, et al. Hamsi scoring in the prediction of unfavorable outcomes from tuberculous meningitis: results of Haydarpasa-II study. Journal of Neurology. 2015;262(4):890-8.

8. Lau KK, Yu I, Chan A, Wong L, Tam CM, Sheng B, Li HL, Hong Kong Tuberculous Meningitis Study Group. A registry of tuberculous meningitis in Hong Kong. The International Journal of Tuberculosis and Lung Disease. 2005;9(12):1391-7.

9. Thwaites G, Fisher M, Hemingway C, Scott G, Solomon T, Innes J. British Infection Society guidelines for the diagnosis and treatment of tuberculosis of the central nervous system in adults and children. Journal of Infection 2009;59(3):167-87

10. Erdem H, Ozturk-Engin D, Elaldi N, Gulsun S, Sengoz G, Crisan A, et al. The microbiological diagnosis of tuberculous meningitis: results of $\mathrm{H}$ aydarpasa-1 study. Clinical Microbiology and Infection. 2014;20(10):600-8

11. Thwaites GE, Bang ND, Dung NH, Quy HT, Oanh DT, Thoa NT, et al. Dexamethasone for the treatment of tuberculous meningitis in adolescents and adults. New England Journal of Medicine. 2004;351(17):1741-51

12. Yasar KK, Pehlivanoglu F, Sengoz G. Predictors of mortality in tuberculous meningitis: a multivariate analysis of 160 cases. The International Journal of Tuberculosis and Lung Disease. 2010;14(10):1330-5

13. Hsu PC, Yang CC, Ye JJ, Huang PY, Chiang PC, Lee MH. Prognostic factors of tuberculous meningitis in adults: a 6-year retrospective study at a tertiary hospital in northern Taiwan. Journal of Microbiology, Immunology and Infection.

\section{0;43(2):111-8}

14. Misra UK, Kalita J, Roy AK, Mandal SK, Srivastava M. Role of clinical, radiological, and neurophysiological changes in predicting the outcome of tuberculous meningitis: a multivariable analysis. Journal of Neurology, Neurosurgery \& Psychiatry. 2000;68(3):300-3

15. Van-Well GT, Paes BF, Terwee CB, Springer P, Roord JJ, Donald PR, et al. Twenty years of pediatric tuberculous meningitis: a retrospective cohort study in the western cape of South Africa. Pediatrics 2009;123(1):e1-8

16. Kalita J, Misra UK. Outcome of tuberculous meningitis at 6 and 12 months: a multiple regression analysis. The International Journal of Tuberculosis and Lung Disease. 1999;3(3):261-5.

17. Centers for Disease Control and Prevention. Treatment of tuberculosis, American Thoracic society, CDC, and Infection Diseases Society of America: Treatment of Tuberculosis. The Morbidity and Mortality Weekly Report (MMWR). 2003;52:1-77. 18. Marais S, Thwaites G, Schoeman JF, Török ME, Misra UK, Prasad K, et al. Tuberculous meningitis: a uniform case definition for use in clinical research. The Lancet Infectious Diseases. 2010;10(11):803-12.

19. Joint Tuberculosis Committee of the British Thoracic Society. Chemotherapy and management of tuberculosis in the United Kingdom: recommendations 1998. Thorax. 1998;53(7):536-48.

20. Gupta M, Bajaj BK, Khwaja G. Paradoxical response in patients with CNS tuberculosis. Journal Association of Physicians of India. 2003;51:257-60.

21. Lanzafame M, Vento S. Tuberculosis-immune reconstitution inflammatory syndrome. Journal of Clinical Tuberculosis and Other Mycobacterial Diseases. 2016;3:6-9.

22. Nhu NT, Heemskerk D, Chau TT, Mai NT, Nghia HD, Loc PP, et al. Evaluation of GeneXpert MTB/RIF for diagnosis of tuberculous meningitis. Journal Clinical Microbiology. 2014;52(1):226-33

23. George EL, Iype T, Cherian A, Chandy S, Kumar A, Balakrishnan A, et al. Predictors of mortality in patients with meningeal tuberculosis. Neurology India 2012;60(1):18 